\title{
Corrective Feedback on Sentence Structure Errors in Writing 4 Class
}

\author{
Kevin Susanto Pokhan
}

English Department, Faculty of Languages and Literature, Petra Christian University, Siwalankerto 121-131, Surabaya 60236, INDONESIA

E-mail: ksus96@gmail.com

\begin{abstract}
This study was done to find out the types of teacher's corrective feedback and the errors in sentence structure that had teacher's feedback on Writing 4A students' first drafts of their four assignments. The writer used theories from Ellis (2009) about written corrective feedback and Ho (2005) about errors in sentence structure. This study was a qualitative study. The source of data was the Writing-4A's four students' first draft of their four assignments. The findings showed that the teacher used one type of corrective feedback: indirect corrective feedback to both groups with Electronic Feedback as the media for group B, and group B made more errors than group A did. Most of the errors were fragmented sentences, and happened when the students wrote compound sentences. In conclusion, the teacher did not differentiate the students in giving feedback, and B-students had more difficulties in creating compound sentences.
\end{abstract}

Keywords: Feedback, Written Corrective Feedback, Errors in Sentence Structure

\section{INTRODUCTION}

One of the main challenges in learning English as a second or foreign language is related to its grammar especially if learners' first language's grammar rules are different from English. Learners might have problems in understanding and applying the grammar rules in their English writing and speaking but still they have to learn to master the rules. As Batstone (1995) says grammar is essenti3al in both written and spoken form.

Students learning English grammar for their written and spoken form might make sentence structure errors in their learning process. This is unavoidable as making errors is considered as a part of learning process. Littlewood $(1984$, p.17) supports the statement by stating that "errors play an important role in learning process. Errors show that the language learners are still building the new knowledge in order to be able to use the language."

Teachers can help their learners to minimize, prevent, and fix their students' grammatical errors by giving feedback. Feedback, according to Keh (1990), is an input from a reader to a writer that provides information for revision. Generally, feedback provides information for teachers and students. Teachers can evaluate their own teaching and know the students' performance through feedback. For students, feedback is an ongoing assessment which focused more on progress than grades. Therefore, feedback becomes an important aspect in the language learning process since it can help the students to develop their language skills by learning from their errors.

There are several reasons why the writer prefers to focus on writing. Writing is important because it is used extensively in formal situations such as higher education and workplace. If the students do not know how to express themselves in writing, they would not be able to communicate with their professors or their working partners in formal situations (Walsh, 2010). Walsh (2010, par. 3) also states that "much of professional communication is done in writing: proposals, memos, reports, applications, preliminary interviews, e-mails, and more are part of 
the daily life of a college student or successful graduate." In writing, sentence structure is important because correct sentence structure can help the readers to understand the meaning of the sentence.

Because of those reasons, the writer aims to see the types of teacher's corrective feedback and the types of errors in sentence structure made by the students in their first draft of their first to fourth assignments. A study by Al-Saadi (2000) about an investigation of writing errors made by high proficiency and low proficiency first year students at Sultan Qaboos University of Oman shows that how teachers give feedback to the error vary depending on the proficiency, showing different types of feedback when responding to the same error types (Al-Saadi, 2000). The study also shows that the students make different number of errors depending on their proficiency level.

This research focuses on finding (1) the types of written corrective feedback that the teacher of Writing 4A class gives to errors in sentence structure in the first draft of the first assignment to fourth assignment and (2) the types of error in sentence structure corrected by the teacher of Writing $4 \mathrm{~A}$ in the first draft of the first assignment to fourth assignment. The theories used for this research are shown below.

\section{Types of Written Corrective Feedback}

\section{Written corrective Feedback (WCF)}

According to Sheen and Ellis (2010, p.593), WCF is a "delayed corrections of errors that students have committed in a written text". It is the type of feedback given by the teacher to the students in essay classes. Ellis (2009) proposed six types of Written Corrective Feedback, namely: Direct Corrective Feedback, Indirect Corrective Feedback, Metalinguistic Corrective Feedback, Focused and Unfocused Feedback, Electronic feedback, and Reformulation.

\section{Direct Corrective Feedback}

Direct corrective feedback is the type of feedback on which "the teacher provides the students with the correct form" (Ellis, 2009, p. 99). Example:

a $a$

A dog stole ${ }^{\wedge}$ bone from ${ }^{\wedge}$ butcher.

\section{Indirect Corrective Feedback}

Indirect Corrective Feedback, as it is stated by Ellis (2009), is a type of feedback given when the teacher does not correct students' error, but rather gives signs that the sentence has error. It "can be done by underlining the errors or using cursors to show omissions in the student's text or by placing a cross in the margin next to the line containing the error" (Ellis, 2009, p.100). Indirect Corrective Feedback can further be divided into coded indirect feedback and uncoded indirect feedback. In coded indirect corrective feedback, the teacher determines the types of errors that has made by the students (i.e. "verb tense"or "spelling"). In uncoded indirect corrective feedback, the teacher underlines or circles the errors and does not write the correct answer to indicate the errors. Ferris and Roberts (2001) said that there is no difference in the students' self-editing performance upon receving coded and uncoded indirect feedback. Example:

A dog stole $\mathrm{X}$ bone from $\mathrm{X}$ butcher. He escaped with Xhaving $\mathrm{X} \mathrm{X}$ bone. When the dog was going $\mathrm{X}$ through $\mathrm{X} X$ bridge over $\mathrm{X}$ theX $\mathrm{X}$ river he found $\mathrm{X}$ dog in the river.

$\mathrm{X}=$ missing word

$\mathrm{X} \_\mathrm{X}=$ wrong word 


\section{Metalinguistic Corrective Feedback}

Ellis (2009) describes metalinguistic feedback as the kind of feedback that gives codes and signs to show the students' nature of error by the means of giving explicit feedback to the students about their error. The most common type of metalinguistic feedback is in the form of codes. The codes given are labels in a form of abbreviations for different kinds of errors. The labels can be put over the location of errors or in the margin in the text, for example, "ww" is for wrong word, "art." is for article, and "prep." is for preposition (Ellis, 2009).

Example:

art. art. WW art.

A dog stole bone from butcher. He escaped with having bone. When the dog was

prep. art. art.

going through bridge over the river he found dog in the river.

Hyland \& Hyland (2019) differentiate indirect and metalinguistic corrective feedback. They stated that metalinguistic feedback is given by showing the nature of errors and how to fix the errors just like the example above. While indirect corrective feedback, as stated by Hyland \& Hyland (2019), is given by showing what and where the error is located; but it requires the students to fix the errors by themselves.

\section{Focused and Unfocused Corrective Feedback}

Ellis (2009) states that focused corrective feedback strategy requires the teacher to select specific error types for correction. For example, the teacher may choose to give feedback to the students in subject-verb agreement. Ellis (2009) argues that focused corrective feedback can help the students in gaining linguistic accuracy.

Unfocused corrective feedback, as Ellis (2009) argues, is the type of feedback which the teacher can choose to give feedback in many kinds of mistakes such as in language use, vocabulary, and content. This type of feedback, therefore, is likely to be more difficult as the students are expected to concentrate in many kinds of errors and to be able to reflect on each mistake. Ellis (2009) believes that unfocused corrective feedback is going to be effective in assisting the students in the long run. This kind of feedback can further be classified to Direct Corrective Feedback, Indirect Corrective Feedback, and Metalinguistic Corrective Feedback (Ellis, 2009).

\section{Electronic Feedback}

Electronic Feedback, as Ellis (2009) describes in his article, is the kind of feedback when teacher indicates an error and gives comments to the file and provides examples of correct usage. This kind of feedback can be accessed through software programs such as Microsoft Word. Therefore, students can be helped by the program whenever they need the feedback. Ellis (2009) stated that this type of feedback needs to be combined to other types of feedback because electronic feedback is used as the media to support other types of feedback.

\section{Reformulation}

Ellis (2009) argues that reformulation is the final option that consists of a native-speaker's version of the part of the sentence that contains an error. In other word, the teacher rewrites all the correct sentences in order to make the language seems as native-like as possible while keeping the originality of the work. Ellis $(2009$, p. 103) states that this type of feedback "aims to provide learners with a resource that they can use to correct their errors but places the responsibility for the final decision about whether and how to correct on the students 
themselves". Even so, this feedback is unfamiliar to be used by the teacher; thus, making it is rarely used.

Sachs and Polio (2007) argues that reformulation is not only a technique for assisting the students with their surface level of linguistic errors; but also designed to draw attention to higher order stylistic and organizational errors. Example:

Original version: As he was jogging, his tammy was shaked.

Reformulation : As he was jogging, his tummy was shaking.

Error correction: As he was jogging his tammy was shaking

\section{Errors in Sentence Structure}

Dangling Modifier: Ho (2005) states that a dangling modifier is a word or phrase that modifies a word unclearly stated in the sentence as the doer of the action is not being clearly stated; thus, making the phrase is termed as a dangling modifier.

Squintling Modifier: Ho (2005) states that a squintling modifier is an unclear modified word when a phrase has been split up unnecessarily, so it is unclear what word is being modified.

Jumbled-up or Illogical Sentences: Ho (2005) states that an illogical sentence is an illogical or jumbled-up ordering of clauses within a sentence.

Incomplete or Fragmented Sentences: Ho (2005) defines fragmented sentence as a subordinate clause which is not linked to the main clauses and stand on their own. Mulvey (2002, p.4) gives further definition of fragmented sentences as "the fragment looks like a sentence because of the capital letter at the beginning and the period at the end, but the fragment is missing either the verb or the subject or both....A sentence must be a complete thought; complete thoughts are the most important thoughts."

Run-On Sentences (Fused Sentence): Ho (2005) defines run-on sentence, or sometimes called as fused sentence, as two independent clauses that are joined together with no connecting word and/or punctuation to separate the clauses.

Inappropriate Coordinating Conjunctions: Ho (2005) describes inappropriate coordinating conjunction is a compound sentence comprising coordinate clauses that are not linked with appropriate coordinating conjunction.

Inappropriate Subordinating Conjunctions: Inappropriate subordinating conjunction, as it is defined by Ho (2005), is a complex sentence comprising subordinate clauses that are not linked by a subordinate conjunction.

Misordering or Inversion of Subject-Verb: Ho (2005) states that inversion of Subject-Verb, also called as misordering, is an incorrect placement of the subject-verb in a sentence or clause. Misordering happens when the inappropriate inversions are used in English sentences. There are some formats that require inversion such as questioning. 


\section{METHOD}

The writer uses qualitative because (1) the instrument of this research is the writer himself, (2) this study uses small samples as the data, (3) the data analysis is done with words, and (4) the study concerns with subjective opinions (Dörnyei, 2007). This study uses four (4) drafts - four (4) drafts from each group of students - for each assignment done by the students as the source of data.

The subjects would be four students. From each student, the writer took four first drafts from the first to fourth assignments. The writer started to collect the students' drafts from the students. Once the writer got the drafts and the scores, he made a copy of the drafts to be analyzed as the source of data and grouped the students based on their Writing 3 final score. On the first and second assignments, the students had written cause-effect essays, and they wrote argumentative essays in their third and fourth assignments.

After collecting the data, the writer read the students' drafts and examined the teacher's feedback to identify the written corrective feedback provided by the teacher to each group and put the result in the findings table for teacher's corrective feedback. After that, the writer took a look on the sentence to identify the errors that had teacher's feedback on each group and put the analysis result on the findings table for errors in sentence structure.

\section{FINDINGS AND DISCUSSIONS}

\section{The Types of Corrective Feedback Given by the Teacher}

The types of corrective feedback given by the teacher on the first to fourth assignments are presented in Table 1. Table 1 shows that from six types of feedback proposed by Ellis (2009), the teacher gave two kinds of feedback: indirect corrective feedback, and electronic feedback. From these kinds of feedback, the most occurrences were the indirect corrective feedback with 25 occurrences; while all the indirect corrective feedback are coded indirect corrective feedback because the teacher gave codes to signify the errors corrected by the teacher.

Table 1: Table of Teacher's Corrective Feedback Types Given to Students' Error

\begin{tabular}{ccccc}
\hline $\begin{array}{c}\text { Corrective Feedback } \\
\text { Types }\end{array}$ & $\begin{array}{c}\mathbf{1}^{\text {st }} \\
\text { assignment }\end{array}$ & $\begin{array}{c}\mathbf{2}^{\text {nd }} \\
\text { assignment }\end{array}$ & $\begin{array}{c}\mathbf{3}^{\text {rd }} \\
\text { assignment }\end{array}$ & $\begin{array}{c}4^{\text {th }} \\
\text { assignment }\end{array}$ \\
\hline $\begin{array}{c}\text { Direct Corrective } \\
\text { Feedback }\end{array}$ & - & - & - & - \\
$\begin{array}{c}\text { Indirect Corrective } \\
\text { Feedback }\end{array}$ & 10 & 3 & 4 & 8 \\
$\begin{array}{c}\text { Indirect corrective } \\
\text { Focused and Unfocused } \\
\text { Feedback }\end{array}$ & - & - & - & - \\
Electronic Feedback & - & - & - & - \\
Reformulation & 9 & - & - & - \\
\hline
\end{tabular}

Table 1 shows the types of corrective feedback given by the teacher. All the corrective feedback in the table is discussed in the points below.

\section{The Types of Corrective Feedback Given by the Teacher to Student A1}

For Student A1, the teacher gave one kind of corrective feedback. The teacher gives corrective feedback as shown below: 
A.1.1.1: [It is a no brainer that crime is everywhere, and it can come from anywhere, but that problem might more rampant in the streets of Indonesia] F

This feedback is considered as an indirect corrective feedback because the teacher gives brackets in the wrong sentence and a letter which signifies the error made by student A1.

\section{The Types of Corrective Feedback Given by the Teacher to Student A2}

For Student A2, the teacher gave one kind of corrective feedback. The teacher gives corrective feedback as shown below:

A.2.3.1: [There at least 17 couples (mostly underage) who got married.] F

This feedback is considered as an indirect corrective feedback because the teacher gives brackets in the wrong sentence and a letter which signifies the error made by student A2.

\section{The Types of Corrective Feedback Given by the Teacher to Student B1}

For Student B1, the teacher gave two kinds of corrective feedback The teacher's corrective feedback are shown in the examples below:

B.1.1.2: That reading book only as a hobby not an obligation $\mathrm{F}$

This feedback is considered as an electronic indirect corrective feedback because the teacher gave the feedback by using Microsoft Word and signified the error by giving an F note on the sentence.

Another feedback is shown below:

B.1.3.1: $\mathrm{R} \mid$ Lastly, the reason why the existence of taxi online should be supported is because taxi online is a good business Economist of the Institute for Development of Economics and Finance (INDEF) Enny Sri Hartati said, the presence of application-based transportation creates opportunities for increasingly extensive employment. This feedback is considered as coded indirect feedback because the teacher gives code to identify the errors in this sentence.

\section{The Types of Corrective Feedback Given by the Teacher to Student B2}

For student B2, the teacher gave two kinds of corrective feedback. The examples are shown below:

B.2.1.2: Because the government corrupts APBN (Anggaran Pendapatan dan Belanja Negara) that makes the poor people cannot get the subsidy for food and healthy. $F$

This feedback is considered as an electronic indirect corrective feedback because the teacher gave the feedback by using Microsoft Word and signified the error by giving an F note on the sentence.

Another kind of corrective feedback is shown below:

B.2.4.1: [Nowadays, parents give anything in term of goods or services to their children that they want.] Dangling Modifier

This feedback is considered as an indirect corrective feedback because the teacher gives brackets to the sentence and signifies the error by writing 'Dangling Modifier' after the brackets. 


\section{The Types of Errors Corrected by the Teacher}

The types of errors corrected by the teacher on the first to fourth assignments are presented in Table 2.

Table 2: Table of Sentence Structure Errors that had Teacher's Corrective Feedback

\begin{tabular}{|c|c|c|c|c|}
\hline Error types & $\begin{array}{c}1^{\text {st }} \\
\text { assignment }\end{array}$ & $\begin{array}{c}2^{\text {nd }} \\
\text { assignment }\end{array}$ & $\begin{array}{c}3^{\text {rd }} \\
\text { assignment }\end{array}$ & $\begin{array}{c}4^{\text {th }} \\
\text { assignment }\end{array}$ \\
\hline Dangling Modifier & - & - & - & 1 \\
\hline Run-on Sentence & - & - & 1 & 1 \\
\hline Illogical Sentence & - & - & - & - \\
\hline Fragmented Sentence & 10 & 3 & 3 & 6 \\
\hline Squintling Modifier & - & - & - & - \\
\hline $\begin{array}{l}\text { Inappropriate } \\
\text { Coordinating } \\
\text { Conjunctions }\end{array}$ & - & - & - & - \\
\hline $\begin{array}{l}\text { Inappropriate } \\
\text { Subordinating } \\
\text { Conjunctions }\end{array}$ & - & - & - & - \\
\hline Misordering & - & - & - & - \\
\hline
\end{tabular}

Table 2 shows that from eight errors proposed by Ho (2005), the students made three kinds of errors: fragmented sentence, dangling modifier, and run-on sentence. From these errors, the most occurrences were the fragmented sentence with 22 errors.

\section{The Types of Errors Made by Student A1}

In his first two assignments, student A1 wrote a cause and effect essays. He made one error each. The error is shown below:

A.1.1.1: It is a no brainer that crime is everywhere, and it can come from anywhere, but that problem might more rampant in the streets of Indonesia.

This sentence is considered as a fragment because there is a missing verb in the last clause. The word 'rampant' is an adjective; therefore, Student A1 should add the verb 'be' after the auxiliary verb 'might'. The sentence should be written: It is a no brainer that crime is everywhere, and it can come from anywhere, but that problem might be more rampant in the streets of Indonesia.

There is no sentence structure error in the third and fourth assignments of Student A1.

\section{The Types of Errors Made by Student A2}

In her first and second assignment on which she wrote cause and effect essays respectively, Student A2 did not make any error related to sentence structure. However, in her third and fourth assignments on which she wrote argumentative essays, student A2 made one error each. The example is shown below:

A.2.3.1: There at least 17 couples (mostly underage) who got married.

This sentence is considered as a fragment because there is a missing verb. To fix this sentence, Student A2 should add a verb after the word 'there'. This sentence should be written: There are at least 17 couples (mostly underage) who got married. 


\section{The Types of Errors Made by Student B1}

In her first two assignments, student B1 wrote cause and effect essays. While in her fourth assignment, she wrote contra essay. On her essays, she made eleven errors of fragmented sentences. From her seven errors, she made three types of fragmented sentences: dependent clause, missing verb, and missing subject. The three kinds of fragmented sentences are shown in the examples below:

B.1.1.2: That reading book only as a hobby not an obligation.

This clause is considered as fragment because there is a missing verb in the clause. To solve this problem we need to add a verb before the conjunction 'only': That reading book only functions as a hobby not an obligation. Here is also another alternative to revise the error sentence: That reading book functions only as a hobby not an obligation.

The second example is shown below:

B.1.2.1: There are 25.95 million people in Indonesia get lower income than the average. This sentence is considered as a fragment because there is a missing subject on the second clause. To fix this sentence, we need to add the missing subject on the second clause: There are 25.95 million people in Indonesia who get lower income than the average.

The third error is shown below:

B.1.4.1: The function of driving license is not only to avoid speeding tickets.

This sentence is considered as fragment because it is a dependent clause. The clause 'not only' needs to be linked to the clause 'but also': The function of driving license is not only to avoid speeding tickets, but also to monitor whether the driver is still eligible to obtain driving license and operating motorized vehicles. Here is another way we can fix the sentence: The function of driving license is not only to avoid speeding tickets, but also to monitor the driver's eligibility to obtain driving license.

In her third assignment, student B1 wrote an affirmative argumentative essay. On her essay, she made 1 error related to sentence structure. The error is shown below:

B.1.3.1: Lastly, the reason why the existence of taxi online should be supported is because taxi online is a good business Economist of the Institute for Development of Economics and Finance (INDEF) Enny Sri Hartati said, the presence of application-based transportation creates opportunities for increasingly extensive employment.

This sentence is considered as a run-on sentence because this sentence needs to be split into two or more sentences. This sentence should be written: Lastly, the reason why the existence of taxi online should be supported is because taxi online is a good business. Economist of the Institute for Development of Economics and Finance (INDEF) Enny Sri Hartati said that the presence of application-based transportation creates opportunities for increasingly extensive employment.

\section{The Types of Errors Made by Student B2}

In her first assignment, student B2 wrote an effect essay. On her assignment, she made two errors of fragmented sentences. The example is shown below:

B.2.1.2: Because the government corrupts APBN (Anggaran Pendapatan dan Belanja Negara) that makes the poor people cannot get the subsidy for food and healthy.

This sentence is considered as a fragment because it is a dependent clause. To make this sentence complete, we need to connect this sentence with an independent clause: Poor people become poorer because they do not get the subsidy to support their daily life because the government corrupts APBN (Anggaran Pendapatan dan Belanja Negara) that makes the poor people cannot get the subsidy for food and healthy. 
In her second assignment, student B2 wrote a causative essay. In this essay, she did not make any errors related to sentence structure. In her third assignment, she wrote a contra essay. On this assignment, she made two errors of fragmented sentences. The errors are shown below: B.2.3.1: There are a lot of women become the victim.

This sentence is considered as a fragment because there is a missing subject on the second clause. To fix this sentence, we need to add a subject to the second clause. This sentence, therefore, should be written: There are a lot of women who become the victim.

The second error is shown below:

B.2.3.2: There is a survey that states $72 \%$ women who do not reporting the sexual harassment so the victims can avoid those consequences and still work or get a new job anywhere.

This sentence is considered as a fragment because there is a missing verb. The word 'reporting' in 'do not reporting' is not a verb; thus, we need to change it into a verb. This sentence should be written: There is a survey that state $72 \%$ women who do not report the sexual harassment so the victims can avoid those consequences and still work or get a new job anywhere.

In her fourth assignment, student B2 wrote an affirmative argumentative essay. She made one dangling modifier and one run one sentence. The errors are shown below:

B.2.4.1: Nowadays, parents give anything in term of goods or services to their children that they want.

This sentence has dangling modifier because there is no clear reference of 'that they want'. This sentence can be fixed by making the clear reference of 'that they want': Nowadays, parents give anything in term of goods or services to their children that the children want.

Another error is shown in the sentence below:

B.2.4.2: They come to the teachers and get angry moreover they hit the teachers.

This sentence is considered as a run-on sentence because it needs to be split into 2 sentences. To fix this sentence, we can put a semicolon to separate the sentence: They come to the teachers and get angry; moreover, they hit the teachers. Another way we can fix this sentence is by separating the sentence with a period: They come to the teachers. Moreover, they hit the teachers.

\section{Interpretations}

From the result above, the errors made by the students were 22 fragmented sentences, 2 run-on sentences, and 1 sentence with dangling modifier. From the total of 25 sentence error, 4 were made by group A-students and 21 were made by group B-students. In the students' assignment, the students were required to make one type of essay for each topic. The group A did not encounter many problems as there were one error each for assignments 1 and 2 by student A1; and there were one error each for assignments 3 and 4 by student A2. The group B, however, had difficulties in their essay as there were many errors found in their essays. For the causeeffect essay, there were more errors when they wrote effect-essays compared to the cause-essays. For the argumentative essays, there were more errors when they wrote the contra essays compared to the pro essays.

The errors made by the A-students were possibly because of they were careless when they wrote their essay; thus, resulting with the little amount of sentence structure errors. The B-students, however, have different cases from the A-students. From the fragmented sentences made by both students B1 and B2, most of the fragmented sentence happened when they wrote compound sentences. This result shows that compound sentences might be difficult for the Bstudents. Judging from the types of the essays, the most errors were made while the students wrote contra essays and effect essays. This result shows that contra essays and effect essays can 
be difficult for the students from group B as there were many errors found in these types of essays.

From the teacher feedback, there were no significant differences as the teacher gave the same feedback to the four students, i.e. indirect corrective feedback to both groups of students. Therefore, there is no much effects caused by the teacher's feedback given to the students.

\section{CONCLUSION}

The findings show that the teacher gave one kind of feedback to all the students: Indirect Corrective Feedback. For students from group B, the teacher used Electronic Feedback as the media for giving indirect corrective feedback. For the students' errors, the most error occurred in the students' writing were fragmented sentences with 22 errors: 4 from group A, and 18 from group B. Majority of the fragments happened when the students created compound sentences. It can also be said that the B-students have difficulties in creating compound sentences. Students from group A did not encounter any problems with the types of the essays and the use of the language. Student A1 made one error each on his first and second assignment on which he wrote cause-effect essays; while student A2 made one error each on her third and fourth assignment on which she wrote argumentative essays. On the other hand, students from group B encountered some problems on some types of essays and in writing compound sentences. Student B1 made 15 errors on her four assignments, while student B2 made 6 errors on her first, third, and fourth assignment. From the essays made by group B, the most errors occurred when they wrote effect essays ( 9 errors) and negative argumentative essays ( 7 errors).

In conclusion, the teacher's feedback has no significant difference when it was applied to group A and group B. Moreover, students from group B might have difficulties in composing compound sentences. They might have difficulties in composing effect essays and contra essays as well. Therefore, students B1 and B2 made more mistakes compared to students A1 and A2. 


\section{REFERENCES}

Al-Saadi, H. (2000). A comparative study of writing errors made by high proficiency and low proficiency first year students at Sultan Qaboos University of Oman. (Unpublished graduate thesis). Bristol: The University of Bristol.

Batsone, R. (1995). Grammar. New York: Oxford University Press.

Dörnyei, Z. (2007). Research method in applied linguistics. New York: Oxford University Press.

Ellis, R. (2009). A typology of written corrective feedback types. ELT Journal, 63(2), 97-107. doi:10.1093/elt/ccn023

Ferris, D. R. \& Roberts, B. (2001). 'Error feedback in L2 writing classes: How explicit does it need to be?'. Journal of Second Language Writing Volume (10), 161-184.

Ho, C. M. L. (2005). Exploring errors in grammar. Singapore: Pearson Education Limited.

Hyland, K. and Hyland, F. (2019). Feedback in Second Language Writing: Contexts and Issues. Melbourne: Cambridge University Press.

Keh, L. C. (1990). Feedback in the writing process: a model and methods for implementation. ELT Journal Volume 44 (4), 294-304. Oxford University Press.

Littlewood, W. (1984). Foreign and second language learning: language acquisition research and its implications for the classroom. New York: Cambridge University Press.

Sachs, R. and Polio, C. (2007). 'Learners' use of two types of written feedback on an L2 writing task'. Studies in Second Language Acquisition 29: 67-100.

Sheen, Y. \& Ellis, R. (2010). Corrective feedback in language teaching. In E. Hinkel (Ed.), Handbook of research in second language teaching and learning. New York: Routledge

Walsh, K. (2010). The importance of writing skills: Online tools to encourage success. Retrieved from http://www.emergingedtech.com/2010/11/the-importance-of-writingskills-online-tools-to-encourage-success/. 